\title{
Arbor
}

\section{El secesionismo austriaco}

\section{Carmen Rocamora García-Iglesias}

Arbor CLXV, 649 (Enero 2000), 21-32 pp.

Estudiamos en este artículo el enigma de la grandeza del sueño vienés, confrontando las obras de sus tres principales representantes: Klimt, Shiele y Kokoschka, que cerraron el s.XIX, y se adentraron con fuerza en el s.XX, mostrándonos su inquietante cambio, mediante los primeros destellos de una luz nueva, nacida en el corazón de la vieja Europa aún poderosa, pese al desgarro de la Primera Guerra Mundial.

KLIMT fué el auténtico creador de la Gran Escuela Vienesa. El carácter extraordinario de su arte consistió en haber logrado una sintesis entre las dos tendencias fundamentales de su momento: el Simbolismo y el Art Nouveau. Su idea fué la "creación de una obra de arte total», grande, moderna y democrática, en la que el progreso de la cultura se basase en una compenetración entre los fines artísticos y los aspectos más diversos de la vida moderna.

Su filosofía, basada en Shopenhauer, reunía las fuerzas de la voluntad con las del mal, afirmando que : «un sincero abrazo a todo el mundo no podía darlo la vida», sino solo el arte liberado de la voluntad.

Su discípulo Shiele, quien sobrevivió al maestro unos meses, (ya que solo vivió durante 28 años), se diferenció enseguida del "deseo de triunfo de la vida», presente en la obra de su profesor, mediante los ejemplos fantasmagóricos que confirió a sus telas, impregnando a sus mejores cuadros de toda la desesperación que es posible transmitir a través de sus torturados personajes.

Y finalmente Kokoschska, hizo que la sustancia misma de su obra, fuese la representación de un siglo, que al menos en dos ocasiones, habia cambiado la faz de Europa, testimoniando con su mirada penetrante la degradación social y cultural del imperio. Secundado por el escritor y periodista Karl Kraus y el filósofo Wittgenstein, realizó imágenes de tal violencia plástica que se le ha considerado como un expresionista austriaco, más que como un auténtico secesionista. 


\section{Introducción}

El Palacio de la Secesión Vienesa, construido bajo el proyecto de José María Ulbrich en 1898, gracias al mecenazgo del industrial Karl Wittgenstein, recoge, en su puerta de ingreso, la idea programática de un grupo de pintores, cuyo punto de unión es la protesta decisiva y caústica contra el historicismo dominante y el deseo de confrontar a la presuntuosa y arcaica sociedad vienesa con las corrientes del arte contemporáneo internacional. Su lema es: «A cada tiempo su arte y, a cada arte su libertad».

Para ello, crearon la llamada «Asociacion de artistas austriacos, 》 cuyo líder e inspirador fué Gustav Klimt, quien tenía como meta, dejar que el arte se desarrollase de forma libre e independiente. Este idearium fue dado a conocer gracias a la publicación de una nueva revista, titulada "Ver Sacrum», en la que, Herman Bahr, se atrevió a escribir: «No tenemos ninguna tradicion, carecemos de frenos conservadores"......

El Ayuntamiento de Viena, regaló el terreno para el Museo de Secesión y el arquitecto Otto Wagner, junto con sus colaboradores y

Figura 1. El Museo de Secesión

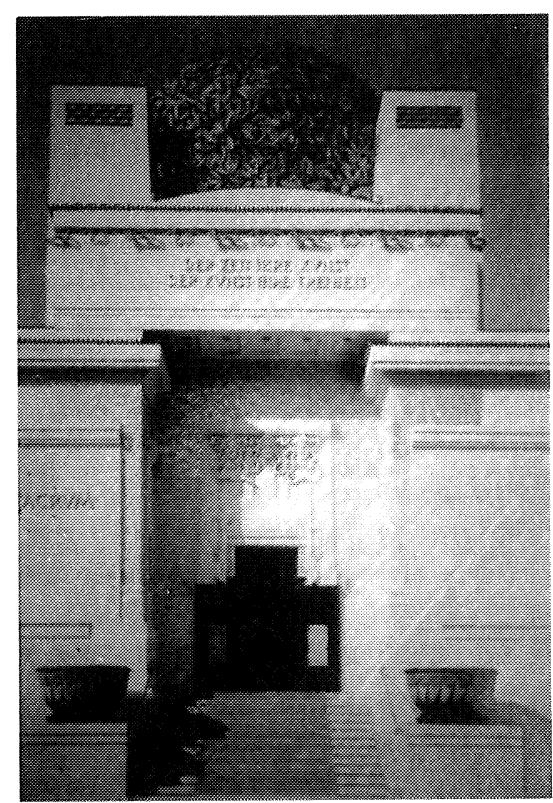


alumnos, llevaron a cabo una sede expositiva, moderna funcional y económica, que fue considerada como un «templo del arte» por sus contemporáneos.

En el curso de los decenios, la Secesión no consiguió mantener el altísimo nivel iniciado por sus fundadores. Periodos de esplendor cultural, (en los que expusieron Rodin, Schiele, Kokoschka, Max Oppenheimer, Frank Marc, El Lissitsky, Chagal , ó Kandinsky), fueron seguidos por otros de crisis y de mediocridad, fundamentalmente debidos a las Guerras Mundiales, durante las cuales, una bomba derribó el lucernario central. Sin embargo, gracias a la colaboracion de numerosos miembros de la Secesión, fue reconstruido, conservándose en la actualidad como símbolo de superación, de triunfo y de esperanza. El responsable, fue, el arquitecto Adolf Krischanity, quien entre 1985-1986, lo dispuso en forma de espacios modulares, ofreciendo la posibilidad de presentar pequeñas y grandes exposiciones, gracias a la flexibilidad de la organizacion espacial, que garantizaba, mediante paneles móviles, la distribucion de muestras de pintura, escultura, video, obra gráfica o fotografía. Sin embargo, para el «Friso de Bethoven», que se presentó en la decimocuarta Exposición de 1902, se creó una sala especial permanente, donde puede verse hoy en día. Esta obra es la mejor y la mas representativa del pintor, que vamos a describir, pieza clave y decisoria de este movimiento revolucionario.

\section{Gustav Klimt}

Las bases en las que se apoyaba la obra de Klimt eran:

1. La gran tradicion simbolista de final de siglo que entendía la pintura como vehículo de expresión de los temas alegóricos y

2. Los elementos representativos, como concepto de ornamentacion, con unidad de estilo y voluntad de recopilación de todas las corrientes del modernismo existente hasta el momento.

Nacido en 1826, empezó su aprendizaje en la Escuela de Artes y Oficios de Viena. Pronto creó un estudio junto con su hermano Ernst, y con Franz Matsch, y, fue en esta época, cuando pintó «La Fábula», $\mathrm{y}$ «El Idilio», siguiendo todavia un discurso simbolista.

En el plano filosófico, se basó en la interpretacion, que, a través del libro «Tractatus», había hecho el joven Wittgenstein de las doctrinas de Shopenhauer, el autor que mayor impacto habia ejercido en el último decenio del XIX, época tan debatida como dubitativa, a causa del espiritu general de incertidumbre reinante, que llevó a Cioran a definirla (años 
después), «como el ensayo general de la crisis de las tradiciones culturales europeas».

En el decenio de 1860, Gustav Klimt, forma un grupo artístico con su hermano Ernst y su amigo Franz Matsch. Este taller, iniciará una carrera precoz en el campo de las decoraciones murales, segun la moda de la época, en la que la sociedad imperial, verá reflejada su propia imagen, como síntesis de su historia, vinculada al pasado y depositaria de todos sus triunfos y sucesos. En esta línea de razonamiento, a Klimt, se le encargó:

1. ${ }^{\circ}$ La decoracion del Burgtheater de Viena, (por lo que se convirtió en el protagonista de la sociedad de su tiempo, recibiendo del Emperador Francisco José, la Gran Cruz de 0ro, en reconocimiento de su actividad pictórica).

2. ${ }^{\circ}$ La escalinata del Kunsthistorisches Museum, (en la que evocó los grandes periodos artísticos de Egipto, Roma y el Renacimiento) y

3. «El Aula Magna» de la Universidad de Viena.

Para el pintor, que dentro del arte oficial había conseguido sus primeros triunfos, suponía una amarga y difícil experiencia personal, el reconciliar esos éxitos oficiales, con las ideas innovadoras que estaban surgiendo en su espíritu, por lo que hay autores que califican al Klimt de este periodo como «Klimt antes de Klimt», es decir, el autor, que no había llegado todavía a la madurez de su estilo, al desprendimiento de los condicionantes sociales y al espiritu desinhibido, adquirido posteriormente, todo lo que le colocaría a la cabeza del movimiento que estamos estudiando.

En el desarrollo de su evolución pictórica encontramos:

1. Una marcada influencia de Makart (que aparece en la obra «Allegorien und Embleme», que realizó en ese periodo).

2. Un realismo idealizado, de corte académico, a la manera inglesa y

3. Una tendencia a copiar los mosaicos bizantinos, que podríamos llamar sus «obras doradas». A esta época pertenecen «El beso», «El Friso de Bethoven» «El retrato de Adele- Bloch -Bauer» etc....

El año 1899 marca la ruptura en el universo artístico de Klimt, dando lugar a su periodo de madurez que le aleja de ser, el epígono de las corrientes oficialistas para transformarse en la personalidad mas singualr del nuevo movimiento austriaco. Sus temas mitológicos «Pallade Atenea» y «Nuda Veritas», son vivos ejemplos de estas caracteristicas que serán constantes en la trayectoria de Klimt. El rompimiento total con la tradicion se concretará en el proyecto de decoración para el Aula Magna de la Universidad de Viena, mediante tres grandes paneles, representantes de la Filosofía, la Medicina, y la Jurisprudencia. 
Figura 2. «El beso» Gustav Klimt

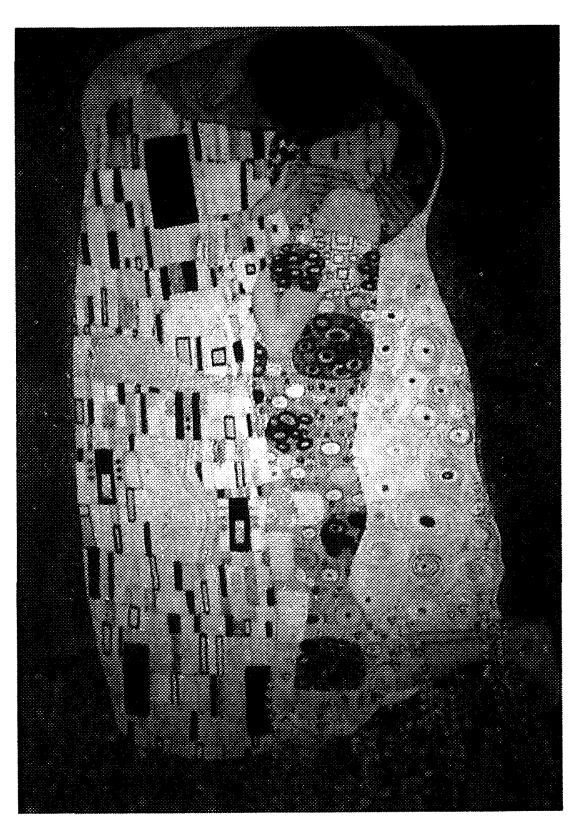

Su hermano Ernst, habia muerto ya, de forma que, fueron Gustav Klimt y Matsch los encargados de llevar a cabo esta obra monumental, que, al no responder a las espectativas del encargo (tradicion positivista e ideas iluministas), causó una reaccion general de estupor y de rechazo en el momento de su presentación.

Vamos a esplicarla:

\section{a) La Filosofía (1901)}

Provocó una carta de protesta firmada por ochenta y siete profesores, que originó el desconcierto en el contexto de la politlca cultural austríaca. En ella, Klimt exponía una imagen del mundo, formada por una amalgama de fuerzas oscuras, contrapuestas por un rostro iluminado, que representaba el conocimiento.

\section{b) La Medicina (1901)}

Dió lugar a tal escándalo, que el proyecto reformista del Ministro de Cultura, Willhelm von Hartel, se vió perjudicado, retirando su apoyo 
a Klimt y refutando ratificar su nómina en la Cátedra de Bellas Artes. En el panel, se exponían una serie de cuerpos fluctuantes, que representaban la Humanidad doliente, condenada a la caducidad y a la muerte, mientras en un primer plano aparecía Higeia, (la Medicina), encarnada por una figura femenina de increible frialdad y belleza, impasible frente a un destino universal, que no le era posible cambiar.

\section{c) La Jurisprudencia (1907)}

Ofrece la figura del ser humano como víctima del laberinto de la administracion judicial. En la parte superior, en un plano ideal, se encuentran la Verdad, la Justicia y la Ley, pero en el espacio inferior, estos tres conceptos se han materializado en tres furias agresivas, que persiguen al hombre, impotente ante ellas. No es de extrañar la reaccion general ante las tres obras, por el abismo que las separaba de las espectativas del encargo.

La evidente modernidad, situan a su autor como la personalidad dominante en estas teorías que se estaban produciendo. En 1847, se crea la Secesión Vienesa, de la que Klimt, será la personalidad dominante y, al mismo tiempo nace el "Ver Sacrum», revista ideológica del movimiento. En los años 1898-1899, se inicia el verdadero periodo de madurez del pintor.

Es entonces, cuando realiza "Pallade Atenea» (tema mitológico), y, un año mas tarde, «Nuda veritas», el desnudo femenino, mas realista, llevado a cabo hasta el momento, en el que la mujer ha sido despojada de toda máscara y representada con la máxima crudeza. Otra obra de la misma época, es la llamada: «Las tres edades de la mujer» (1905), por la que le fué concedida la Medalla de Oro de la Exposicion Internacional de Arte de Roma en 1911. En esta obra establece con escueta simplicidad una reflexión abismal de orden filosófico, representando el deterioro de Cronos en la naturaleza humana, mediante una síntesis entre: la mujer niña - la mujer creadora de vida- y la mujer portadora de muerte, dentro de un ambiente simbolista que irradia un magnetismo hipnótico y destructivo. El ciclo alegórico de Klimt, se cierra con "El Friso de Bethoven», concebido para la decimo-cuarta Muestra de la Secesión (1902).

La exposición se convirtió en un homenaje al compositor que encarnaba el paradigma romantico del artista demiurgo. El tema, expresado por Klimt, se basa en la interpretacion simbólica de la Novena Sinfonía, apoyandose en la poesía de Schiller a través de sus versos del «Himno a la alegría». En su inauguracion, Gustav Mahler, dió un 
FIgURA 3. "Las tres edades de la mujer» Gustav Klimt

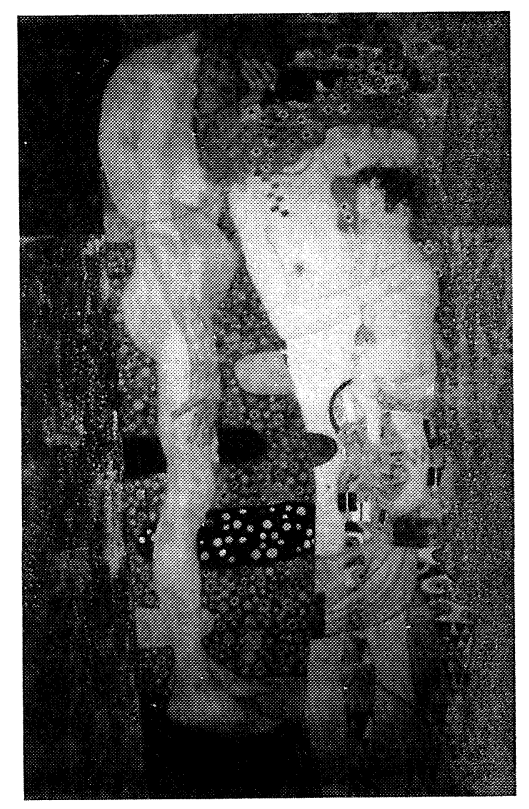

concierto con una vision totalmente personal de la obra, en un arreglo para instrumentos de cuerda.

El pensamiento de Shopenhauer y de Nietzsche, en la concepción del Friso, viene determinado, por la forna de interpretación que Wagner hace de Bethoven. De hecho, el concepto de la musica como entidad mediadora por excelencia que abre la conciencia al mundo instintivo, es un tema recurrente en la obra de Klimt. Por esta epoca, descubre los mosaicos bizantinos, durante un viaje a Ravenna, dando lugar al llamado «Periodo áureo», con el que el artista manifiesta su proceso evolutivo personalísimo, en un corto espacio de tiempo, dentro de su produccion.

En 1902, se celebra la Primera Kunstchau, en la que Klimt, entra en contacto con Oskar Kokoschka. Al año siguiente era ya un artista tan valorado que presidió la Segunda Kunstchau dedicada al arte extranjero contemporáneo. En ella conoció a Van Gogh, Munch, Gauguin, Matisse, Bonnard y Veuillard.

En la primavera de 1901, había pintado «El Beso», uno de sus cuadros mas admirados y conocidos. El tratamiento del oro, lo aborda 
con un acento ambi-valente, por una parte, a traves de la supremacía de los símbolos geométricos para evidenciar la función alegórica del elemento narrativo, pero a su vez, basándose en un código de signos abstractos nuevos, elocuentes de su trasformación.

El final de este proceso áureo, concluye en la decoración del palacio del banquero Adolf Stoclet en Bruselas. Paradógicamente el sueño secesionista, de un arte «hecho por todos» $\mathrm{y}$ "destinado a todos», ricos y pobres, tuvo un destino final radicalmente opuesto a esta iniciativa, es decir, fué a parar a un espacio estrictamente privado y residencial, el salón de estar del acaudalado banquero Stoclet.......

En los seis ultimos años de su vida, Gustav Klimt, rompe con el simbolismo dorado para evolucionar hacia una técnica pictórica radicalmente nueva, llena de antecedentes fauvistas, en la que el color se enriquece de una fluida sensualidad.

El dinamismo en la composicion y la soltura en la ejecución, caracterizan las escenas alegóricas de este periodo final. A excepción de la obra "Adan y Eva», todas las demás («Vida y muerte», «La Virgen», «El Niño», «La corte nupcial»), parecen variaciones de un mismo ciclo.

Evidentemente la obra de Klimt está basada en la influencia de Shopenhauer, como ya se ha dicho. Herman Bahr, a través de la Revista Ver Sacrum, se había dedicado a la difusión de las ideas de este filósofo, así como al desarrollo de las teorías de Nieszche, de Wagner y de Wittgenstein, quien basándose en la epistemología Kantiana, precisaba los límites internos de la razón, dejando fuera el campo de la metafísica.

Ahora bien, la obra del famoso pintor no fué una transcripcion literal del pensamiento del filósofo. A Shopenhauer hay que interpretarle en el contexto ideológico del Movimieneo Secesionista, y en este sentido, los paneles del Aula Magna que se han descrito, (la Justicia, la Medicina y la Filosofía,) estan basados en esa ideología de tristeza y desencanto. Sin embargo, otras veces, ( como en el Beso, El campo florido, Las Amapolas etc...), el artista inclina su paleta hacia un idealismo de factura hedonista.

Peter Altemburg aclama a Klimt como el filósofo y poeta moderno, pues reconoce en su pintura, la capacidad de «revelar la interna existencia del mundo en un lenguaje, cuya propia razon no comprende» ............... para ello, recurre, desde el historicismo ecléctico de la tradicion simbolista, hasta la estilización de la ornamentacion, de forma semejante a lo que aconsejó el filósofo Wittgenstein en su Tractatus: «el encuentro entre el retrato y el escenario del hombre en su vida diaria, no es, sino un matrimonio contra natura»... 


\section{El secesionismo austriaco}

Quizá ambos personajes, el pensador y el artista, nacidos en un paisaje comun y en un tiempo semejante, son espejos divergentes, con destinos diversos, pero cuyos reflejos, confluyen fatalmente hacia la penumbra de la misma duda y de la misma inquietud.

\section{Egon Shiele}

Conoció a Klimt, cuando Shiele tenía diez y siete años y Klimt cuarenta y cinco. Este último, quedo impresionado por la profundidad y el carácter de su joven amigo, hasta el punto de invitarle a formar parte en Exposiciones tan importantes como: la Internacional Kuntschau de Viena (1909), la de Secesion de Munich (1912), y la Kuntlerhaus de Budapest. Igualmente fué admitido en la Liga de Artistas Austriacos de la que era presidente Klimt (1913), y posteriormente, pese a su juventud, fué encargado de organizar y seleccionar la Exposicion de la Secesión de 1918, en la que el artista participó con 19 óleos y 29 obras en papel.

FIgURA 4. "Madre con dos hijos» Egon Shiele

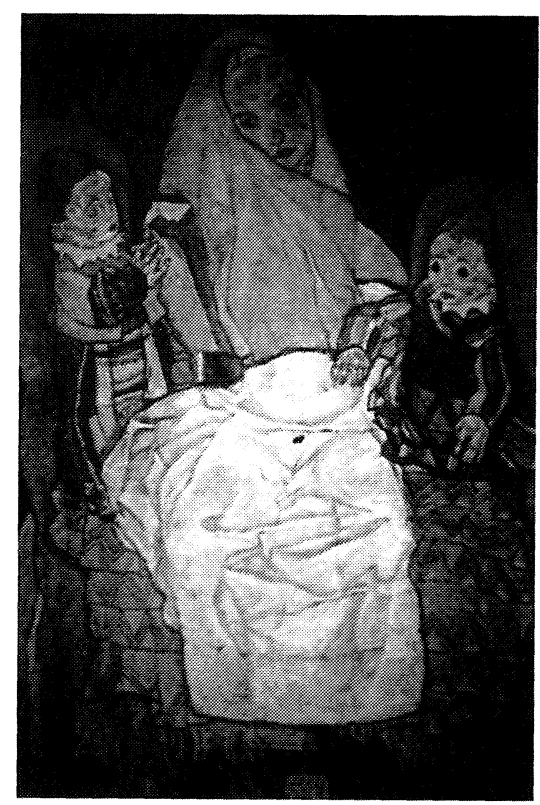


Fué tal la admiración de Shiele por el gran creador del Secesionismo Vienés, que a la muerte de éste, el 6 de Febrero de 1918, Shiele, le retrató en su lecho de muerte. .........Paradogicamente, por esos sucesos tan inesperados de la vida, el joven alumno, solo sobrevivió al maestro unos meses, ya que el 31 de Octubre de ese mismo año (1918), murió Shiele,cuando solo contaba ventiocho años de edad

\section{Kokoschka}

Se inició en el Secesionismo y el Modernismo, participando, como hemos mencionado anteriormente en las Kuntschau de 1908-1909 junto con Klimt y Shiele. Fué contemporáneo de estos autores, pero su larga vida (18886-1981), le hizo convivir con otros movimientos vanguardistas posteriores, por lo que Kokoschka, gracias a su evolución posterior, es considerado, más que como secesionista-modernista, como el mejor representante austriaco del Expresionismo Aleman.

La filosofía de Wittgenstein y la de Adoft Loos, (su principal mecenas), están en la raiz de su pintura. A través de este último, entra en contacto con Herwarth Walden, principal promotor del Expresionismo, quien le contrata para llevar a cabo las ilustraciones de su revista, por lo que Kokoschka, se traslada a la capital alemana, entrando en contacto con los principales exponentes de «El Puente» y «El Jinete Azul».

Es entonces, cuando el vienés, se propone una tarea, llena de violencia plástica, que ningun otro artista se habla atrevido a desafiar: la biografía interior del siglo que le habia tocado vivir, a través de retratos, en los que recoge imágenes crispadas y llenas de desolación, (como el de Montesquieu-Frezenac, en el que enmascara la premonición de su muerte, bajo una digna elegancia aristocratica).

Es así como pinta gran parte de los personajes de la alta burguesía, en lo que él llamó "pinturas negras», pues, de acuerdo con las ideas psicoanalistas de Freud, «pintaba la suciedad del alma» de los personajes que reproducía.

Su obra:«El retrato de Alma Malher», (viuda del compositor y posteriormente amante de Rilke y de Gropius), refleja el apasionado idilio que sostuvo con ella, durante algun tiempo, que alcanza su representación de máxima fuerza en "La Tempestad», una alegoría wagneriana, en la que el pintor se representa a sí mismo con su amada, en una relacion turbulenta y apasionada. 


\section{El secesionismo austriaco}

FIGURA 5. «La Tempestad» Kokoschka

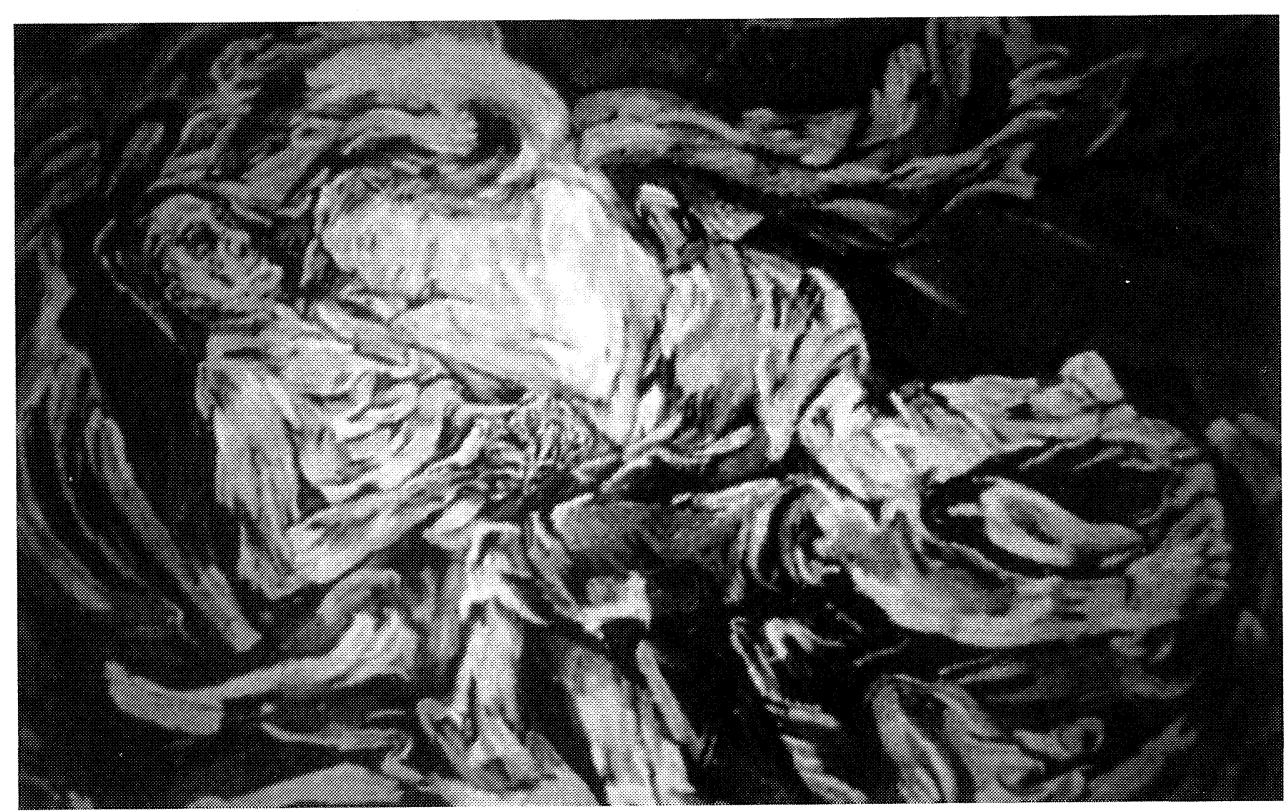

Herido en la Primera Guerra Mundial y recuperado, tras pernanecer en un hospital de Dresde entre 1916-1923, viaja por Europa, Africa y Oriente Medio para recalar en Paris. Tiempo después regresa a Viena y mas tarde a Praga, ciudad atravesada por el rio Moldava, especialmente querida para Kokoschka, ya que fué allí donde conoció a la que habría de ser su mujer Olda Palkovska.

Instalado en una vieja torre a las orillas del río, contemplaba la belleza de la ciudad, con sus Iglesias del XVI, sus edificios y sus puentes, que más tarde, representaría en una obra llena de belleza y sentimentalismo titulada: «La Praga nostálgica», cuando ante la inminente ocupación nazi, tuvo que salir huyendo, dejando reflejado en el cuadro, una parte de su vida, irrecuperable y perdida, ya que Kokoschka, nunca volvió a esta ciudad, por ser considerado por Hitler, como uno de los «Artistas Degenerados», y su obra recluida en los sótanos de los museos. El asesino de masas, demostraba su arrogante ignorancia en materia de arte, condenando una de las vanguardias mas importantes y espectaculares del s. XX. 
Kokoschka se trasladó a Inglaterra, gracias a haber adquirido la nacionalidad checa y allí, pintó «Londres, Chelsea Reach», (1957), momento, a partir del cual, ya nadie discutió su madurez artistica siendo invitado cada verano, desde 1955 a 1963, a dar unos cursos de pintura en Salzburgo en la llamada «Escuela de la Vista».

La premonición de su muerte inminente, le hizo concebir la vida con «una conciencia de superviviente», y así expresó en los cuadros de esta etapa, su afán de denuncia y la tristeza que le había producido contemplar el mundo en pleno desmoronamiento.

Sin embargo la esperanza y la defensa de los valores de la libertad no habían muerto todavía en su alma doliente, por ello, en los últimos seis años de su vida, se dedicó a pintar un ciclo de alegorías, al modo de los pintores del XVII, en recuerdo de la mejor joya del Barroco Austríaco, el Monasterio de Melk, cerca de donde Kokoschka había pasado su infancia, en recuerdo del «mundo al que le gustaria regresar, pero que ya habia dejado de existir».

En esta etapa, titulada «La saga de Prometeo», se alejó a través de la imaginación y la fantasía al plano de la mitología, tan distante del mundo que se había derrumbado ante sus propios ojos, en un intento de huir, del horror y la desolación que habían dominado su existencia.

Fué, su canto del cisne, de esperanza y libertad para enseñar al mundo, la necesidad de surgir de sus propias cenizas, olvidando el pasado y mirando al frente, en una nueva valoracion de la vida a través de la espiritualidad y el esfuerzo.

\section{Bibliografía}

Coradesch, Sergio: «La obra pictórica completa de Klimt». Bditorial Noguer. S.A. Paseo de Gracia 96. Barcelona. (1981).

Faerna García Bermejo: «Kokoschka 1886-1980». Globus Gomunicación. Madrid. Ediciones Polígrafa. Barcelona. (1994).

Forsthuber Sabine: «La Secessionne Viennese». CIP. Kurztitelaufnahme der Deutschen Bibliothek. Viena. (1988).

Fullea Fernando: «Klimt, Kokoschka, Schiele, un sueño vienés. (1898-1918). ”. Fundación Juan March. (1995).

Garas, Klara: «The Budapest Gallery». Corvina Press. Printed in Hungary. Kossuth Printing House. Budapest. (1977).

Huici, Fernando: «Klimt». Editoriale Giorgio Mondadori. Milán. (1989).

The SOLOMON GUGGENHEIM Foundation: "Works of Art of the Guggenheim Foundation". New York. (1991).

Vienna Museums in colour: Pinguin-Verlag, Innsbruck. Austria. (1986). 